\title{
New coincidence between Shroud of Turin and Sudarium of Oviedo
}

\author{
C. Barta ${ }^{1, a}$, R. Álvarez² , A. Ordóñez ${ }^{2}$, A. Sánchez ${ }^{3}$, and J. García ${ }^{2}$ \\ ${ }^{1}$ Research Team of Spanish Center of Sindonology (EDICES), Madrid, Spain \\ ${ }^{2}$ EDICES, University of Oviedo, Oviedo, Spain \\ ${ }^{3}$ EDICES, Murcia, Spain
}

\begin{abstract}
The Sudarium of Oviedo and the Shroud of Turin are two relics attributed to Jesus Christ that show a series of amazing coincidences announced in the past. In this contribution, we describe the X-ray fluorescence analysis carried out on the Sudarium. Among the chemical elements detected, calcium shows a statistically significant higher presence in the areas with bloody stains. This fact allows correlating its distribution with the anatomical features of the corpse. A large excess of calcium is observed close to the tip of the nose. It is atypical to find soil dirt in this zone of the anatomy, but it is just the same zone where a particular presence of dust was found in the Shroud. The very low concentration of strontium traces in the Sudarium matches also well with the type of limestone characteristic of the rock of Calvary in Jerusalem. This new finding adds to others recently released and it strengthens the tradition that both cloths have wrapped the body of Jesus of Nazareth.
\end{abstract}

\section{Introduction}

According to tradition, the Sudarium of Oviedo is a relic of Christ. In fact, it has been called "Sudario del Señor" (Cloth of the Lord) for centuries. For an introduction to the Sudarium of Oviedo see Guscin [1] and Rodríguez-Almena [2]. The forensic analysis of the cloth leads to the conclusion that it was used around the head of a corpse stitched to its hair and its beard. First, the corpse was in an upright position, bleeding pulmonary oedema by mouth and nose. Afterwards the deceased man was lain face down. Then it was slightly shaken around and finally, some minutes later, the cloth was removed and sprinkled with aloes and styrax, a substitute of myrrh. If this reconstruction is correct, the Sudarium would have been used before the corpse was covered with a shroud.

The Shroud of Turin is another of the best known Christ's relics according to tradition [3, 4]. If it was used with the same personality as the Sudarium of Oviedo, the stains and dust of the body would leave similar traces in both cloths. In fact, a series of amazing coincidences between the two cloths has been already described.

In this contribution, we communicate a new decisive coincidence recently discovered by the X-ray fluorescence. We also recall other similarities maybe not widely known.

\footnotetext{
${ }^{a}$ Corresponding author: cbartagi@cofis.es
}

This is an Open Access article distributed under the terms of the Creative Commons Attribution License 4.0, which permits unrestricted use, distribution, and reproduction in any medium, provided the original work is properly cited. 


\section{Previous coincidences between Shroud and Sudarium}

A series of definitive coincidences between the Sudarium of Oviedo and the Shroud of Turin have been discovered in various specialties of the scientific research [5-8]. Both cloths have been used for a bearded man with moustache and longhair arranged behind in a ponytail. The Shroud shows a crucified man and the corpse of the Sudarium died in an upright position. Moreover, in both cases, the executed man was tortured with a crown of thorns. Finally, in both instances, the blood corresponds to the scarce type AB.

Some challenging aspects of the Shroud could be explained if the victim also used the Sudarium of Oviedo: For example, the strands of hair close to the cheeks in a more or less horizontal arrangement can be justified by the fixative use of the Sudarium as it has been experimentally verified by one of the authors [9]. Concurrently, the above alleged "ponytail" would be a result of the attachment and sewing of the Sudarium around the central-back strand of hair.

In this contribution we show the results of the X-ray fluorescence applied to the Sudarium of Oviedo. The primary goal of the X-ray fluorescence detection is to estimate the relative amount of some chemical elements through the different areas of the cloth: This analysis provided a new fascinating coincidence with an already known fact concerning the Shroud of Turin.

\section{Instrumentation and experimental procedure}

This experiment is based on the fact that X-rays reaching the atoms that compose an object can remove an electron from its orbit. Electrons removed from the inner shells (K and L) are replaced by those from the outer orbits. In the process, a characteristic photon is emitted and, if properly detected, it can be used to identify the source element. A high resolution detector determines the number of photons per time unit that occur with that particular energy.

The experiment design was created considering the results of previous forensic research developed by Villalaín [10]. It concluded that the "reverse" side of the Sudarium was in contact with the head of the victim. The left half was in direct contact from the beginning with the nape, the area of the left ear and the face. The right half was, however, folded over the left half during this first stage enabling this right half to be directly exposed to the environment. Considering that the body was lain face down for some time, the right half of the cloth could have also been in direct contact with soil. Afterwards, the cloth was arranged all around the head and the right half also contacted directly the head over the right ear area.

With these premises in mind, the analysis was performed on 57 spots of the reverse side following a pattern of points distribution predetermined. Spots included blood stains and clean areas of the two halves. Figure 1 shows the situation of every measured spot.

The measurements were performed by Rodrigo Álvarez in the Oviedo Cathedral (where the Sudarium is preserved) on two instances: 40 measurement spots on 9th March 2012 and 17 measurement spots on the following day 10th March 2012. It took more than an hour and a half in a whole. We implemented a regular grid of $2 \times 2 \mathrm{~cm}$ cells to locate every spot: with the origin of coordinates positioned in the lower left corner of the Sudarium; X range from 0 to $84 \mathrm{~cm}$ and $Y$ from 0 to $52 \mathrm{~cm}$.

We used a portable Fluorescence X-ray detector Niton XL3t (Fig. 2). The simplicity and the suitability to apply this equipment in situ were the main reasons to select this detector. The unit has a screen and an internal register of the data that allows further processing in the laboratory. The voltage selected was $50 \mathrm{kV}$ with a current of $40 \mu \mathrm{A}$. Measurement time for each spot was 60 seconds except for the two last (\#742 and 743) that lasted $90 \mathrm{~s}$ and 105 s, respectively. A gold anode and a circular window of $11 \mathrm{~mm}$ of diameter equivalent to an area of $0.95 \mathrm{~cm}^{2}$ were used.

Among the several modes of operation available on the detector, the Standard Soil Mode was selected for the experiment. Following the manufacturer instructions, this mode of operation is optimum 


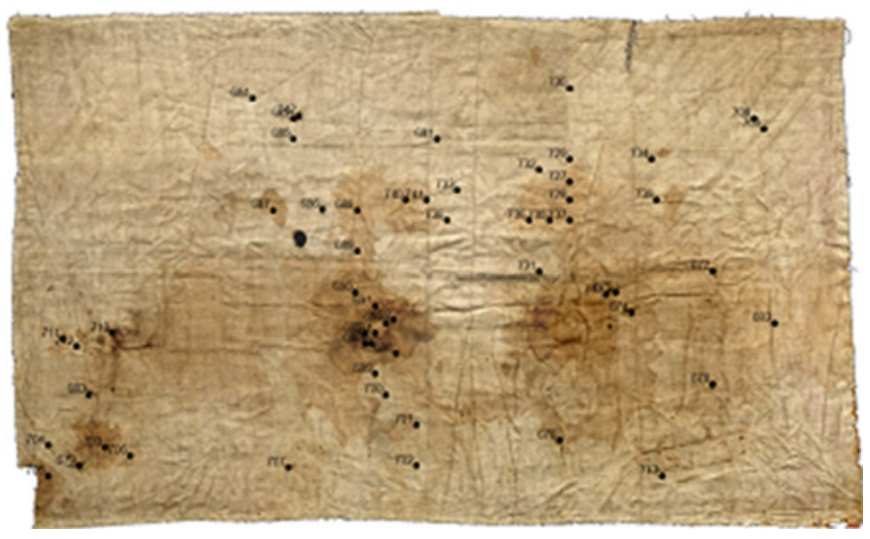

Figure 1. Location of measurement spots on the reverse side of the Sudarium of Oviedo. The reference numbers are listed in Table 3, in the "label" column.

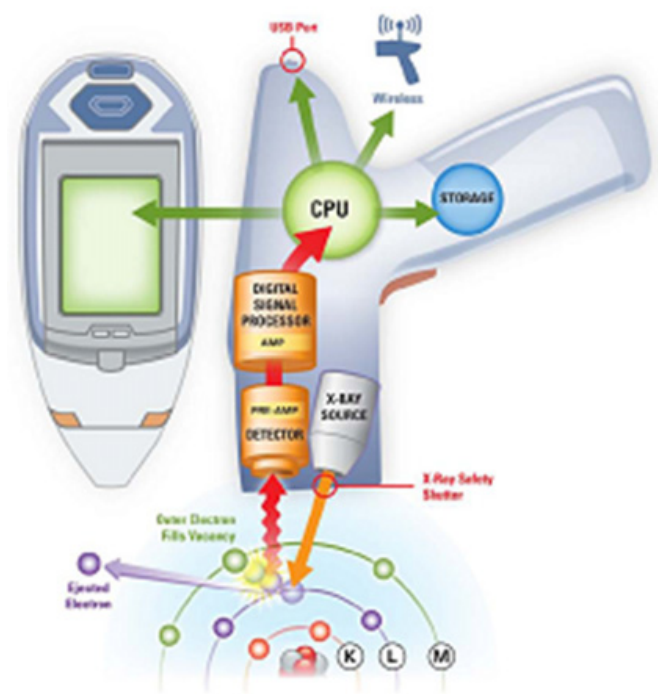

Figure 2. Fluorescence X-ray detector scheme included in the unit manual (@NITON).

for the analysis of contaminants present at less than $1 \%$ inside light matrix, if other elements with atomic number greater than that for iron present in this matrix do not exceed several percent. This mode of operation was selected considering that we were looking for elements that could be mineral particles constituents of the dust and items related to the various liquids present in the fabric of the Sudarium of Oviedo.

Many elements can be detected by the equipment with atomic numbers greater than $16(\mathrm{~S})$ in the actual experimental conditions. Given that none of the main elements of the basic substance of the cloth (cellulose) can be detected by this method, the elements detected must be components of contamination and impurities. However, the reliability of the measurement depends on the signal to noise ratio: when the detector finds the same signal level for an element than for the noise, it automatically assigns zero existence of the element. Moreover, there are other criteria to definitively accept the presence of an element when it is detected by the unit. We can compare the average level of values obtained for each 


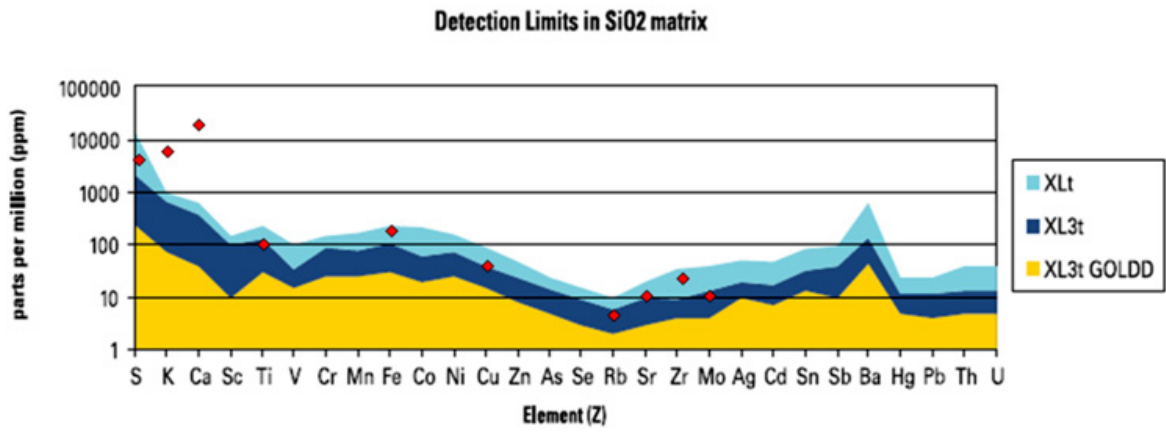

Figure 3. Average amount of detected elements (red points) versus their detection limits (CNITON) for the XL3t detector used in the test.

element with the Limits Of Detection (LOD) communicated by the manufacturer (Fig. 3). In this case, we find good reliability for the measurement level of calcium $(\mathrm{Ca})$ and potassium $(\mathrm{K})$. Just only a few ppm over the limit are sulfur (S), iron (Fe) and zirconium ( $\mathrm{Zr}$ ). During the test, the cloth was on a table made of glass whose main component is $\mathrm{SiO}_{2}$ approaching the conditions to those of LOD indicated by the manufacturer. However, we consider in the data analysis that the measurements of the Sudarium can include some photons coming from the table impurities. In any case, we recorded the detection of many other elements as they can be useful especially if we want to know the distribution model of the pollution associated to the fabric surface for a specific element. With this information, the relative concentrations of observed elements can be correlated with visible features on the cloth.

We analyzed also several samples of the Calvary rock and the stones of the Oviedo's cathedral using the same portable detector. Some of the Calvary samples were analysed in other facility with a Fischerscope X-ray XDV SDD, 2010. In this case, the voltage selected was also $50 \mathrm{kV}$ with a current of $128 \mu \mathrm{A}$, a collimator diameter of $1 \mathrm{~mm}$ and a Nickel filter.

\section{Previous tuning tests}

To verify the reliability of our data analysis on the Sudarium of Oviedo, we performed three control tests:

i) On samples of modern linen fabric that had been stored several years in the laboratory allowing contamination from the environmental dust.

ii) On samples of old fabrics linen dated between end of XIX century and first half of the XX century, from different origins.

iii) On a modern cloth in which contamination with different amounts of calcium carbonate (powder of travertine aragonite) was deposited. This last test was made considering the possibility that the Sudarium of Oviedo could have dust from the Calvary in Jerusalem whose local rock is limestone. Dust from the Cathedral of Oviedo is also abundant in limestone and this could also justify its presence in the Sudarium surface.

The significant values are showed on Tables 1 and 2.

The presence of $\mathrm{Ca}$ and $\mathrm{Fe}$ is detectable and it is consistent with the hypothesis that they come from environmental dust. The presence of small quantities of rubidium ( $\mathrm{Rb}$ ) and titanium (Ti) exclusively in modern linen should be considered without interest for this kind of test on old cloths. The presence of Ti in modern linen may be linked to a possible use of pigments with Ti for bleaching the flax. Finally, the presence of zinc $(\mathrm{Zn})$ in one of the old cloths is out of the scope of this study. We remark the absence of 
Table 1. Data analysis on three modern linen fabric (ppm).

\begin{tabular}{|l|c|c|c|c|c|c|}
\hline & \multicolumn{3}{|c|}{ modern 1 } & \multicolumn{2}{c|}{ modern 2 } & \multicolumn{2}{c|}{ modern 3 } \\
\cline { 2 - 7 } & Data & Error & Data & Error & Data & Error \\
\hline $\mathrm{Ca}$ & 3732 & 103 & 3626 & 102 & 3595 & 103 \\
\hline $\mathrm{Fe}$ & 765 & 34 & 801 & 35 & 820 & 34 \\
\hline $\mathrm{Rb}$ & 117 & 3 & 106 & 3 & 97 & 3 \\
\hline $\mathrm{Ti}$ & 9167 & 107 & 8736 & 105 & 7937 & 101 \\
\hline
\end{tabular}

Table 2. Data analysis on four old linen fabric (ppm).

\begin{tabular}{|l|c|c|c|c|c|c|c|c|}
\hline & \multicolumn{3}{|c|}{ Old cloth C } & \multicolumn{2}{|c|}{ Old cloth P } & \multicolumn{2}{c|}{ Old cloth G1 } & \multicolumn{2}{c|}{ Old cloth G2 } \\
\cline { 2 - 9 } & Data & Error & Data & Data & Data & Error & Data & Error \\
\hline $\mathrm{Ca}$ & 1353 & 95 & 1056 & 99 & 134 & 83 & 1222 & 96 \\
\hline $\mathrm{Fe}$ & 3806 & 57 & 6142 & 72 & 4424 & 61 & 4028 & 58 \\
\hline $\mathrm{Zn}$ & 93 & 6 & & & & & & \\
\hline
\end{tabular}

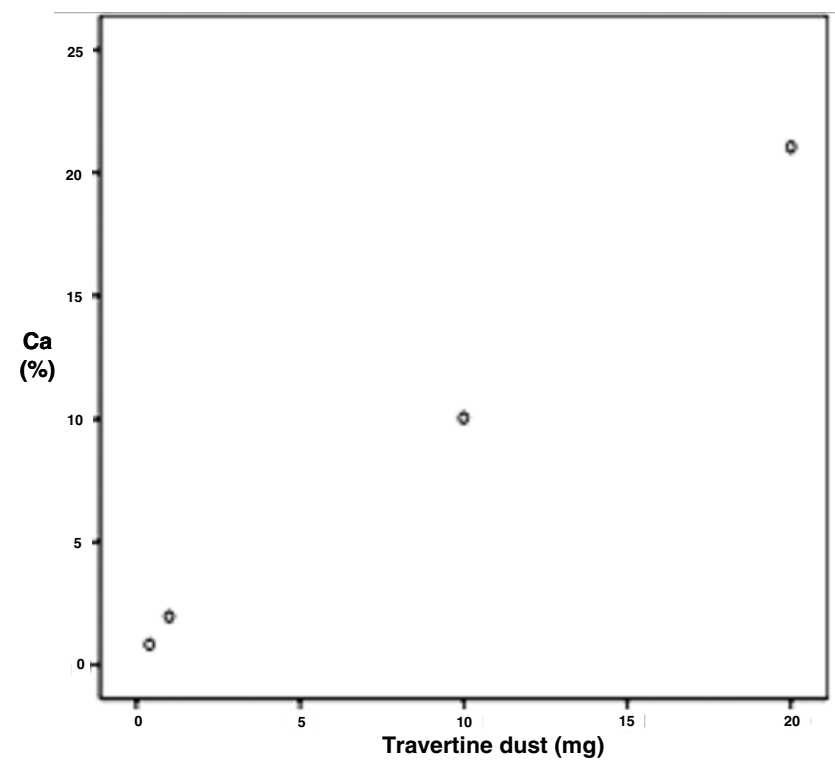

Figure 4. Correlation between the amount of travertine dust poured onto a linen cloth and the amount of $\mathrm{Ca}$ measured with the Niton XL3t detector.

biological-related elements although these elements are detectable by the Niton X13t if they are present in enough quantity.

The proportionality between the amount of deposited powder and the Ca detected was verified (Fig. 4). The two points with the lowest Ca percentage in that figure are representative of data found in the Sudarium.

\section{Results and data analysis}

The values obtained in each measured spot of the Sudarium of Oviedo are exposed in Table 3. First column shows the label of the spot given by the device; $\mathrm{X}$ and $\mathrm{Y}$ stand for the coordinates of the 
Table 3. Data analysis for the Sudarium of Oviedo (ppm).

\begin{tabular}{|c|c|c|c|c|c|c|c|}
\hline Label & $\mathbf{X}(\mathbf{c m})$ & $\mathbf{Y}(\mathbf{c m})$ & $\mathrm{Ca}(\mathrm{ppm})$ & K (ppm) & $\mathbf{S}(\mathbf{p p m})$ & $\mathrm{Fe}(\mathrm{ppm})$ & $\mathrm{Sr}(\mathrm{ppm})$ \\
\hline 674 & 61.0 & 22.8 & 14817 & 12429 & 8322 & 150.3 & 9.52 \\
\hline 675 & 59.5 & 24.9 & 15545 & 20108 & 10581 & 135.5 & 6.28 \\
\hline 676 & 54.0 & 9.9 & 17322 & 6139 & 5614 & 146.0 & 11.43 \\
\hline 677 & 69.0 & 27.0 & 15684 & 7181 & 5143 & 148.6 & 9.91 \\
\hline 678 & 69.0 & 15.6 & 15701 & 4191 & 4954 & 181.5 & 10.19 \\
\hline 679 & 7.0 & 7.3 & 20227 & 8387 & 5867 & 165.7 & 13.24 \\
\hline 680 & 8.0 & 14.5 & 21603 & 6039 & 6607 & 208.1 & 14.82 \\
\hline 681 & 42.0 & 40.5 & 14758 & 6024 & 4089 & 185.2 & 11.21 \\
\hline 682 & 28.0 & 42.6 & 9956 & 8921 & 4791 & 143.9 & 10.38 \\
\hline 683 & 75.0 & 21.8 & 20124 & 2536 & 2241 & 180.3 & 12.58 \\
\hline 684 & 24.0 & 44.7 & 12311 & 2273 & 2575 & 174.3 & 10.85 \\
\hline 685 & 28.0 & 40.5 & 12342 & 2154 & 1345 & 174.0 & 11.72 \\
\hline 686 & 30.8 & 33.3 & 13143 & 2408 & 1372 & 176.4 & 12.88 \\
\hline 687 & 26.0 & 33.2 & 18481 & 2373 & 3703 & 177.2 & 11.53 \\
\hline 688 & 34.2 & 33.2 & 21205 & 3444 & 2350 & 181.1 & 13.19 \\
\hline 689 & 34.2 & 29.1 & 13559 & 3710 & 2681 & 169.8 & 11.58 \\
\hline 690 & 34.0 & 24.9 & 17932 & 4820 & 2976 & 200.8 & 10.86 \\
\hline 691 & 36.0 & 23.6 & 14670 & 5439 & 3531 & 157.6 & 10.93 \\
\hline 692 & 37.8 & 22.1 & 26211 & 7093 & 6062 & 200.3 & 12.84 \\
\hline 693 & 37.0 & 21.8 & 50393 & 7372 & 3745 & 257.6 & 16.37 \\
\hline 694 & 36.0 & 20.8 & 31627 & 7155 & 2831 & 160.1 & 12.41 \\
\hline 695 & 35.0 & 20.8 & 18643 & 6790 & 4247 & 222.3 & 11.78 \\
\hline 696 & 35.0 & 19.7 & 20215 & 6132 & 5192 & 228.5 & 11.64 \\
\hline 697 & 35.6 & 19.7 & 15252 & 5949 & 3424 & 178.4 & 11.45 \\
\hline 698 & 38.0 & 18.7 & 18021 & 6992 & 4005 & 207.2 & 11.75 \\
\hline 699 & 36.0 & 16.6 & 18864 & 6181 & 6168 & 212.4 & 12.02 \\
\hline 700 & 37.0 & 14.5 & 15480 & 5918 & 4372 & 197.8 & 11.23 \\
\hline 701 & 40.0 & 11.4 & 17089 & 6292 & 5255 & 165.3 & 11.1 \\
\hline 702 & 40.0 & 7.3 & 15126 & 6171 & 4029 & 168.6 & 11.21 \\
\hline 703 & 9.6 & 9.1 & 22343 & 4838 & 2634 & 177.7 & 13.58 \\
\hline 704 & 4.0 & 9.3 & 19292 & 4356 & 3215 & 141.3 & 12.46 \\
\hline 705 & 4.0 & 6.2 & 25426 & 3419 & 2334 & 173.3 & 13.05 \\
\hline 706 & 12.0 & 8.3 & 23682 & 4802 & 2799 & 148.0 & 12.94 \\
\hline 707 & 27.5 & 7.1 & 19199 & 5067 & 4172 & 336.4 & 12.59 \\
\hline 708 & 73.0 & 42.6 & 13752 & 2752 & 3071 & 164.1 & 10.33 \\
\hline 709 & 74.0 & 41.5 & 17742 & 2734 & 3488 & 233.0 & 10.93 \\
\hline 710 & 10.3 & 20.8 & 31228 & 6239 & 3966 & 275.6 & 14.22 \\
\hline 711 & 5.5 & 20.3 & 25699 & 4492 & 3309 & 160.8 & 13.99 \\
\hline 712 & 6.8 & 19.4 & 20347 & 4545 & 5758 & 159.4 & 14.04 \\
\hline 713 & 64.0 & 6.2 & 12831 & 5984 & 4038 & 141.1 & 11.34 \\
\hline 727 & 55.0 & 36.1 & 20101 & 6989 & 5127 & 178.5 & 11.65 \\
\hline 728 & 55.0 & 34.3 & 21010 & 7032 & 5521 & 190.6 & 11.91 \\
\hline 729 & 55.0 & 38.4 & 18756 & 6354 & 3171 & 201.6 & 9.93 \\
\hline 730 & 55.0 & 45.7 & 19618 & 4806 & 4782 & 179.6 & 11.2 \\
\hline 731 & 52.0 & 27.0 & 21180 & 8197 & 5469 & 242.1 & 11.76 \\
\hline 732 & 52.0 & 37.4 & 18397 & 6300 & 3730 & 178.9 & 10.68 \\
\hline 733 & 44.0 & 35.3 & 11380 & 4498 & 2216 & 151.2 & 9.87 \\
\hline 734 & 63.0 & 38.4 & 17270 & 4432 & 3190 & 171.9 & 11.23 \\
\hline 735 & 53.0 & 32.2 & 20967 & 7649 & 7024 & 166.5 & 12.57 \\
\hline 736 & 51.0 & 32.2 & 23573 & 8268 & 5830 & 181.4 & 11.95 \\
\hline 737 & 55.0 & 32.2 & 21342 & 6859 & 4227 & 204.7 & 12.09 \\
\hline 738 & 43.0 & 32.2 & 13267 & 4189 & 2960 & 150.2 & 10.51 \\
\hline 739 & 63.5 & 34.3 & 16580 & 4090 & 4714 & 152.8 & 10.38 \\
\hline 740 & 39.0 & 34.3 & 15104 & 3745 & 2009 & 179.5 & 10.02 \\
\hline
\end{tabular}


Table 3. Continued

\begin{tabular}{|l|l|l|l|l|l|l|l|}
\hline 741 & 41.0 & 34.3 & 13592 & 3733 & 1957 & 173.5 & 11.18 \\
\hline 742 & 28.5 & 42.9 & 12008 & 6283 & 3598 & 170.1 & 11.32 \\
\hline 743 & 58.5 & 24.7 & 15901 & 15610 & 9239 & 145.0 & 8.39 \\
\hline Mean & $\mathbf{1 8 7 3 5}$ & $\mathbf{5 9 4 5}$ & $\mathbf{4 2 3 9}$ & $\mathbf{1 8 2 . 2}$ & $\mathbf{1 1 . 6}$ \\
\hline \multicolumn{2}{|l}{ Standard deviation } & $\mathbf{6 2 1 6}$ & $\mathbf{3 0 3 4}$ & $\mathbf{1 8 2 0}$ & $\mathbf{3 5 . 9}$ & $\mathbf{1 . 6}$ \\
\hline
\end{tabular}

Table 4. Data from the support table (ppm).

\begin{tabular}{|l|l|l|l|l|l|}
\hline Label & Ca $(\mathbf{p p m})$ & $\mathbf{K}(\mathbf{p p m})$ & $\mathbf{S}(\mathbf{p p m})$ & $\mathbf{F e}(\mathbf{p p m})$ & $\mathbf{S r}(\mathbf{p p m})$ \\
\hline 114 & 16169 & 2025 & < LOD & 433.96 & 35.51 \\
\hline 115 & 16589 & 1956 & < LOD & 400.13 & 34 \\
\hline 116 & 16433 & 1959 & < LOD & 435.03 & 33.59 \\
\hline 117 & 16968 & 1980 & < LOD & 452.4 & 34.56 \\
\hline 119 & 16649 & 1967 & < LOD & 457.67 & 34.72 \\
\hline 121 & 16857 & 1914 & < LOD & 444.4 & 34.3 \\
\hline 122 & 16914 & 1801 & < LOD & 435.95 & 34.07 \\
\hline 123 & 16664 & 1985 & < LOD & 446.41 & 35.4 \\
\hline 124 & 17214 & 1926 & < LOD & 466.05 & 34.36 \\
\hline 125 & 17024 & 1995 & < LOD & 434.33 & 36.28 \\
\hline 128 & 17201 & 1992 & < LOD & 438.83 & 33.77 \\
\hline Mean & 16789 & 1954 & - & 440.47 & 34.60 \\
\hline Standard deviation & 323 & 59 & - & 17.04 & 0.82 \\
\hline
\end{tabular}

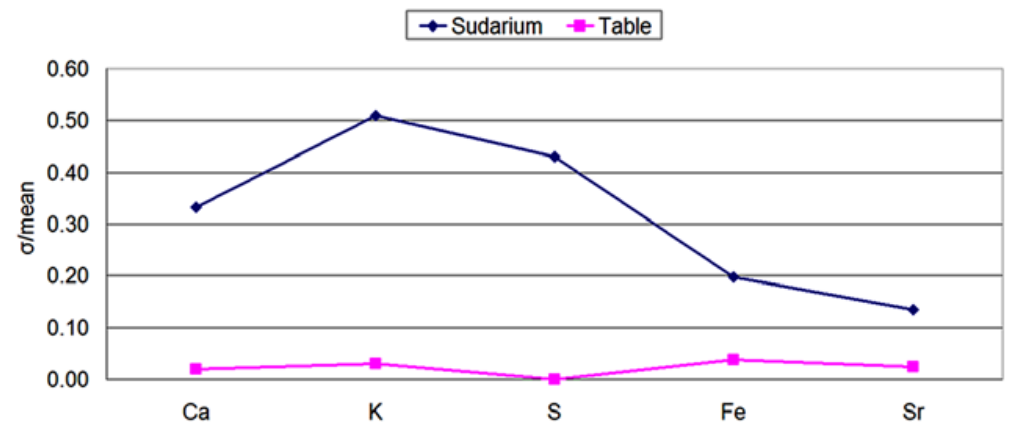

Figure 5. Ratio between standard deviation $(\sigma)$ and mean for both, the supporting table and the Sudarium.

measuring point according to the above mentioned grid. Next columns show the measurement values obtained.

Before we go further in the data analysis, we evaluate the impact of the table used as support for the cloth. We measured 11 spots along the table surface without the Sudarium on it. The unit detects the presence of all the elements found in the Sudarium except for sulfur (see Table 4).

But all the spots from the supporting table present very similar measurements corroborating that the background is uniform enough. Figure 5 shows the ratio between standard deviation $(\sigma)$ and mean for both, the table and the Sudarium.

The variability of concentrations detected in the Sudarium considerably overcomes the variability of concentrations detected in the supporting table. The Fisher Snedecor test presented in Table 5 and conducted for evaluate if the variance of the two set of measures is significantly different confirms the visual impression. 


\section{SHS Web of Conferences}

Table 5. Fisher-Snedecor test for variances of table and cloth.

\begin{tabular}{|l|c|c|l|}
\hline Label & $\begin{array}{c}\text { Ratio of } \\
\text { variances }\end{array}$ & $\begin{array}{c}\text { F-test criteria } \\
(0.05)\end{array}$ & Result \\
\hline Ca (ppm) & 370 & 2.63 & Different \\
\hline K $(\mathbf{p p m})$ & 2576 & 2.63 & Different \\
\hline $\mathbf{F e}(\mathbf{p p m})$ & 4.45 & 2.63 & Different \\
\hline $\mathbf{S r}(\mathbf{p p m})$ & 3.64 & 2.63 & Different \\
\hline
\end{tabular}

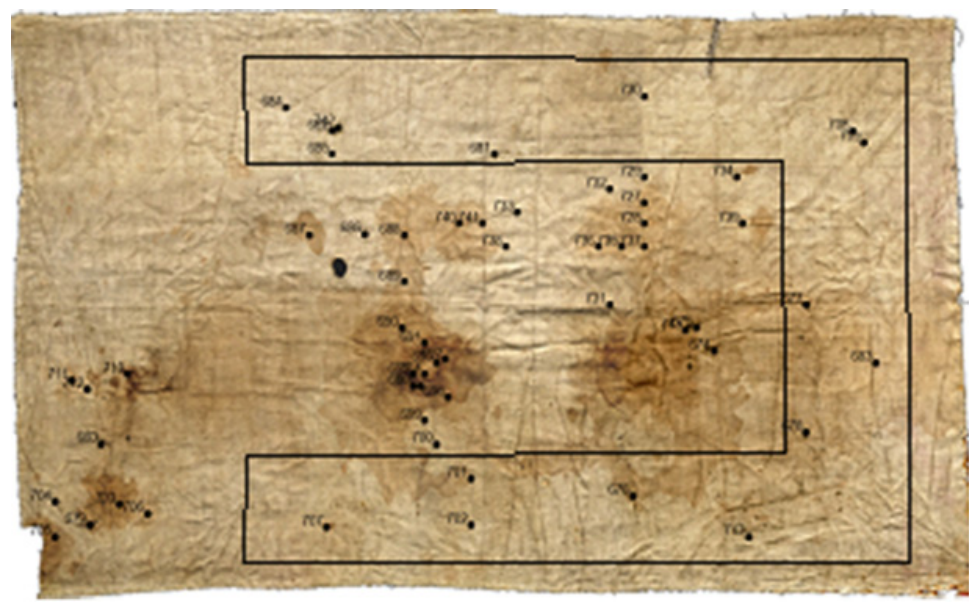

Figure 6. Area considered as "clean" (in contrast to stained area) in the interpretation of analytical results.

Thereby, the concentrations detected in the spots of the Sudarium can be useful if they are considered as relative concentrations. The concentrations of $\mathrm{Ca}, \mathrm{K}$ and $\mathrm{S}$ detected in the Sudarium are higher than those detected in the table, evidencing that there is more concentration of these elements in the former. The opposite occurs with iron and strontium $(\mathrm{Sr})$, as the concentrations detected in the Sudarium are lower than those detected in the table alone. This suggests that the concentrations of these two elements in the cloth must be even lower than the values recorded, as a portion may come from the table.

Once verified the validity of our data, we can progress with the analysis. Spots 674,675 and 743 correspond to two rectangular stains produced by a contamination from the bottom of a painting tin. A previous analysis of these points detected Ag [11]. Our analysis did not include silver detection, but the signal for mercury $(\mathrm{Hg})$ at these three points - and only for these three - was significant and exceeded the LOD (133 ppm, $154 \mathrm{ppm}$ and $144 \mathrm{ppm}$ respectively). These spots also show the highest level of K and $\mathrm{S}$ confirming the painting-related nature of these stains. Thereby, these three points were excluded from the statistical analysis.

For the other points, we found interesting to separate the measurement on the blood stains from those on the "clean area" mainly in the periphery. The clean area is defined in the Fig. 6 and includes 16 points. The amount of points on stains is 38 .

The quantities detected in the stained area and in the clean area are shown in Table 6 and Fig. 7. In this figure we represent the mean values with their standard deviations as a percentage of the mean found in clean spots. So, the mean values for the clean area are the $100 \%$ reference but the mean values found in stains result higher than that reference for all the analysed elements.

For further assessment, we performed the following t-Student test at $95 \%$ of confidence level to determine whether the differences between the values in the stain and clean areas are statistically 


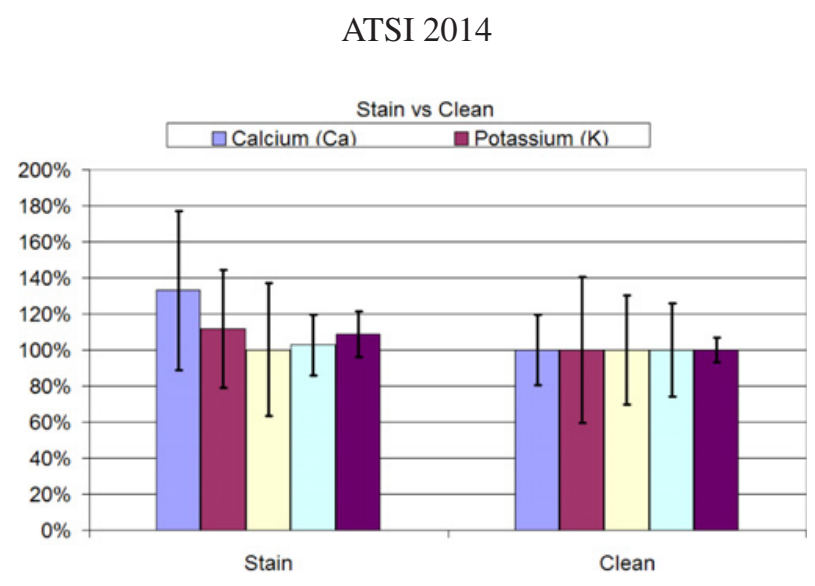

Figure 7. Mean value with its standard deviation for main elements at clean and stain groups, as a percentage of the value found for the clean group.

Table 6. Test of significant difference between groups clean and stains (ppm).

\begin{tabular}{|l|c|c|c|c|c|c|l|}
\hline Element & $\begin{array}{c}\text { Mean } \\
\text { clean }\end{array}$ & $\begin{array}{c}\text { Sigma } \\
\text { clean }\end{array}$ & $\begin{array}{c}\text { Mean } \\
\text { stains }\end{array}$ & $\begin{array}{c}\text { Sigma } \\
\text { stains }\end{array}$ & $\begin{array}{c}\text { Mean } \\
\text { differe. }\end{array}$ & criterion & result \\
\hline Calcium & 15348 & 3017 & 20423 & 6782 & 5075 & 3556 & different \\
\hline Potassium & 4969 & 2010 & 5559 & 1628 & 590 & 1045 & similar \\
\hline Sulphur & 3949 & 1186 & 3955 & 1453 & 6 & 826 & similar \\
\hline Iron & 180.7 & 46.9 & 185.8 & 30.4 & 5.0 & 21.5 & similar \\
\hline Strontium & 11.14 & 0.75 & 12.12 & 1.41 & 0.98 & 0.75 & different \\
\hline
\end{tabular}

significant:

$$
\begin{aligned}
\text { Different if } & \left|\mathrm{m}_{1}-\mathrm{m}_{2}\right|>\mathrm{t}_{\text {student }}\left(5 \%, \mathrm{n}_{1}+\mathrm{n}_{2}-2\right)^{*} \sigma_{\text {dif }} \\
\text { Similar if } & \left|\mathrm{m}_{1}-\mathrm{m}_{2}\right| \leq \mathrm{t}_{\text {student }}\left(5 \%, \mathrm{n}_{1}+\mathrm{n}_{2}-2\right)^{*} \sigma_{\text {dif }} .
\end{aligned}
$$

Where:

$\mathrm{m}_{\mathrm{i}} \quad$ mean of the group $\mathrm{i}$

$\mathrm{n}_{\mathrm{i}} \quad$ number of elements of the group $\mathrm{i}$ (16 in clean spots and 38 in stains)

$$
\sigma_{\mathrm{dif}}=\sqrt{\frac{\sigma_{1}^{2} \cdot\left(n_{1}-1\right)+\sigma_{2}^{2} \cdot\left(n_{2}-1\right)}{n_{1}+n_{2}-2}\left(\frac{1}{n_{1}}+\frac{1}{n_{2}}\right)}
$$

$\sigma_{i} \quad$ standard deviation of the group i.

The results of this test for the elements analysed are shown in Table 6. The differences between the concentrations detected in the clean and stained area are statistically significant only for $\mathrm{Ca}$ and $\mathrm{Sr}$. In particular spot 693 in the stained area shows the highest concentration leading to the new decisive coincidence discussed below.

If we consider that the two groups of data can have different variances, the Welch test is more appropriated, but it provides the same classification of similarity.

Spots $682,742,686,733,677,678,681,676,701$ and 707 could not strictly belong to the area where they were classified in Fig. 6 and they can change from one group to the other. Considering the different alternatives of the clean and the stained group we also detected significant differences in the concentration of $\mathrm{K}$ and S. Furthermore, the presence of $\mathrm{K}$ is singular for the Sudarium because it is 


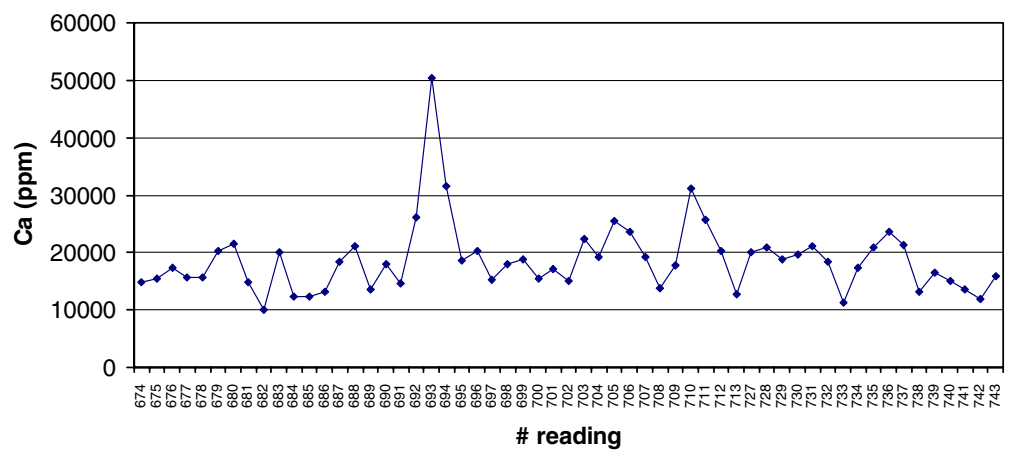

Figure 8. Content of calcium for every measured spot on the Sudarium.

present neither in modern cloths nor on the old cloths considered as control samples (see Table 1 and Table 2). The higher concentrations of $\mathrm{K}$ and $\mathrm{S}$ detected on the stained areas confirm the physiological nature of the stains.

But the most evident difference between the stained and the clean area is the content of Ca which is always higher in the former. A possible origin of the surplus of $\mathrm{Ca}$ is the environmental dust deposited along the history of the Sudarium. Nevertheless, this hypothesis does not seem very reliable as we would expect a homogeneous distribution of it along the fabric or a correlation with its conservation mode. Thereby, we consider that the excess of the particles with $\mathrm{Ca}$ on the stained areas were fixed to the cloth by the physiological fluids while they were still fresh. The correlation between $\mathrm{Ca}$ and the stains is very important as the stains have been linked with the anatomical part of the deceased man [10] and therefore, the amount of $\mathrm{Ca}$ can be also linked some way with the anatomical parts.

\subsection{The new significant coincidence for dust}

Here we highlight the main finding of this investigation. The aforementioned measured spot (693) shows a particularly high quantity of $\mathrm{Ca}(5.1 \sigma$ away from the mean). We do not consider it a mistaken lecture as the two closest spots (694 and 692) show the second and the forth highest content of Ca (see Table 3 and Fig. 8).

The three mentioned spots belong to the stained group and the detected Ca would have been fixed by the physiological fluid while it was still fresh. Figure 9a shows an estimated matching between the Shroud of Turin face and the Sudarium stains and the location of 692, 693 and 694 spots. These spots are close to the tip of the nose. On the other hand, we can assume that the calcium is associated to soil dirt and so, the nose is an atypical part of the body to present this singular dirt. But just, an unexpected excess of dirt around the tip of the nose was also detected in the Shroud of Turin providing an astonishing coincidence with the Italian cloth. Figure 9 allows the comparison between the Ca content detected in this study (Fig. 9a) and the homologous results obtained by the X-ray fluorescence conducted in the Shroud [12], Fig. 9b. We can see a light excess of Ca close to the tip of the nose also in the Shroud.

Previous literature concerning the investigation of the dirt of the nose in the Shroud of Turin is reproduced here after:

"Detailed photographs and microscopic studies of the cloth in the nose image area show scratches and dirt. These are consistent with the nose having made contact with the ground, most likely as the result of a fall" $[13,14]$.

"Visual observation of the heel area at 500 times magnification revealed the presence of very fine yellowish particles suggesting dirt; the nose area might also contain dirt or residual skin material." [15]. 

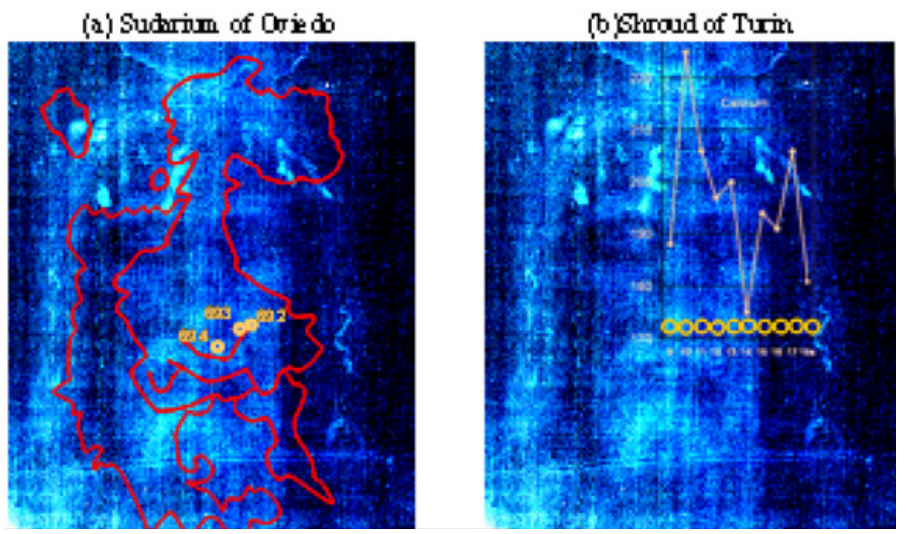

Figure 9. Estimated matching between of the Shroud of Turin face and the Sudarium stains and the location of 692, 693 and 694 measured spots. (b) Intensity of Calcium on the face of the Shroud elaborated from Morris et al. (1980).

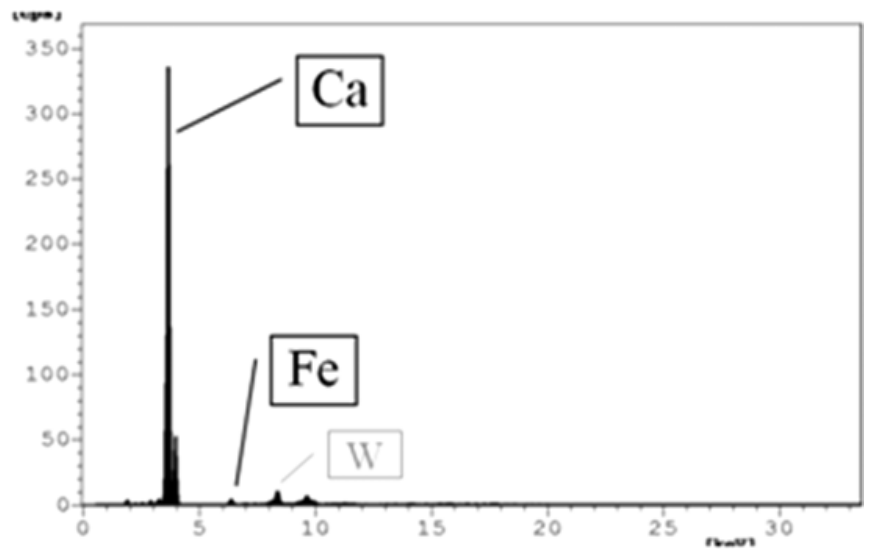

Figure 10. X-ray fluorescence of a sample of the Calvary of Jerusalem.

"Pellicori and Evans noted significantly higher concentrations of particulates in the nose and foot regions of the image. In these areas, X-ray fluorescence indicated statistically significant excesses of iron above background levels" [16].

\subsection{Origin of the limestone dust}

We try now to asses the possible origin of the limestone retained in the Sudarium analysing its impurities. $\mathrm{Ca}$ is obviously very common in limestone soils, but two hypotheses deserve consideration: it can come from the Calvary and it can come from the Oviedo's Cathedral. We measured X-ray fluorescence on several samples from the Calvary and from the cathedral stones. Concerning the X-ray fluorescence analysis performed in the Calvary samples, the results show it is a very pure limestone with few impurities, as it is observed in Fig. 10. Only a small peak corresponding to Fe escorts the Ca peaks. Other minor peaks at $8.3 \mathrm{keV}$ and $9.7 \mathrm{keV}$ are artifacts from the tungsten sample holder.

Morris, Schwalbe and London [12] also affirm that the presence of $\mathrm{Ca}$ and $\mathrm{Sr}$ in their results is due to dust accumulation. The $\mathrm{Sr}$ detected in our analysis can be an indicator of the type of limestone deposited 
Table 7. Ratio strontium to calcium concentrations for Sudarium and limestone from Oviedo cathedral and Calvary.

\begin{tabular}{|l|c|}
\hline Origin & Sr/Ca $\times \mathbf{~ 1 0 3}$ \\
\hline Cathedral limestone & 2.43 \\
\hline Calvary limestone & 0.24 \\
\hline Clean area of Sudarium & 0.75 \\
\hline Stained area of Sudarium & 0.63 \\
\hline
\end{tabular}

on the Sudarium. We can assess similarity between the ratio $\mathrm{Sr} / \mathrm{Ca}$ detected in the Sudarium and those from the Calvary and Oviedo's Cathedral. Given that Sr do not have a biological origin, if detected in the Sudarium, it must come from mineral impurities. Table 7 shows the different $\mathrm{Sr} / \mathrm{Ca}$ ratios calculated for the Calvary, for Oviedo's Cathedral and for the Sudarium (separating between stained and cleaned areas).

The ratios detected in the Sudarium are more similar to the Calvary's ratio than to the Cathedral's ratio suggesting a stronger similarity with the former. As we explained before, we consider that the fluids, when still fresh, acted as cement for the environmental dust and thereby the stained area should have a higher proportion of mineral particles from the place where it was used. The ratio in the stained area of the Sudarium is even closer to the Calvary limestone ratio. These results lead to the hypothesis that over $75 \%$ of the limestone deposited in the Sudarium comes from the Calvary attributing only the rest to the Cathedral. Moreover, the level of $\mathrm{Sr}$ detected in the cloth of Oviedo can be overestimated as some of it may come from supporting table, as it was indicated in previous paragraph.

Nevertheless, as Schwalbe and Rogers [16] said, the X-ray fluorescence measured by Morris et al. [12] showed also a singular excess of iron, particularly on the blood stains. Our data do not show any specific distribution for iron. This is an unexpected result because blood has been confirmed on the Sudarium even with the detection of red blood cells [17]. This fact deserves further research. The first inquiries lead to involve the influence of the supporting glass table as the responsible of a low sensibility for iron.

\section{Other less known coincidences}

Apart from the coincidences between the Sudarium of Oviedo and the Shroud of Turin mentioned in the introduction and from the new presented in this work, we would like highlight some other coincidences recently announced but not widely known.

First coincidence is related to the form of the hair. In the back of the Man of the Shroud the hair is apparently arranged in a "ponytail" shape. It falls between the shoulder blades down to the half of his back. This hairstyle has often been attributed to a typically Jewish fashion in the time of Christ $[3,4]$. However, it seems unlikely that the hair remains in its place after undergoing the torture observed directly in the Shroud. Moreover, there is no evidence in the image of any artifact holding the tuft in such a shape. A simpler and more probable explanation is provided by Barta [9]: the "ponytail" is the result of the use of the Sudarium of Oviedo which was placed and sewed around the hair in this area.

Following Barta [9], the edge of the Sudarium was placed at the level of the cervical vertebrae covering the hair of the victim (Fig. 11). In order to hold the cloth in this position it was sewn with linen thread to the hair on the back of the head. Some threads still remain in the Sudarium today. The seam can be deduced by two relatively parallel lines of holes where the needle went in and out. The hair bundle remained tied up in this way for about two hours. Dirty hair soaked with blood and sweat and retained in this position for two hours preserves afterwards the given shape. This was experimentally verified with volunteers with long hair, which was covered with serum, dust and blood. We observed how the hair hardened when the blood dried. Once the Sudarium was carefully removed from the corpse, the hair of the back should maintain its ponytail shape. If this Sudarium was used for the same corpse than in the 


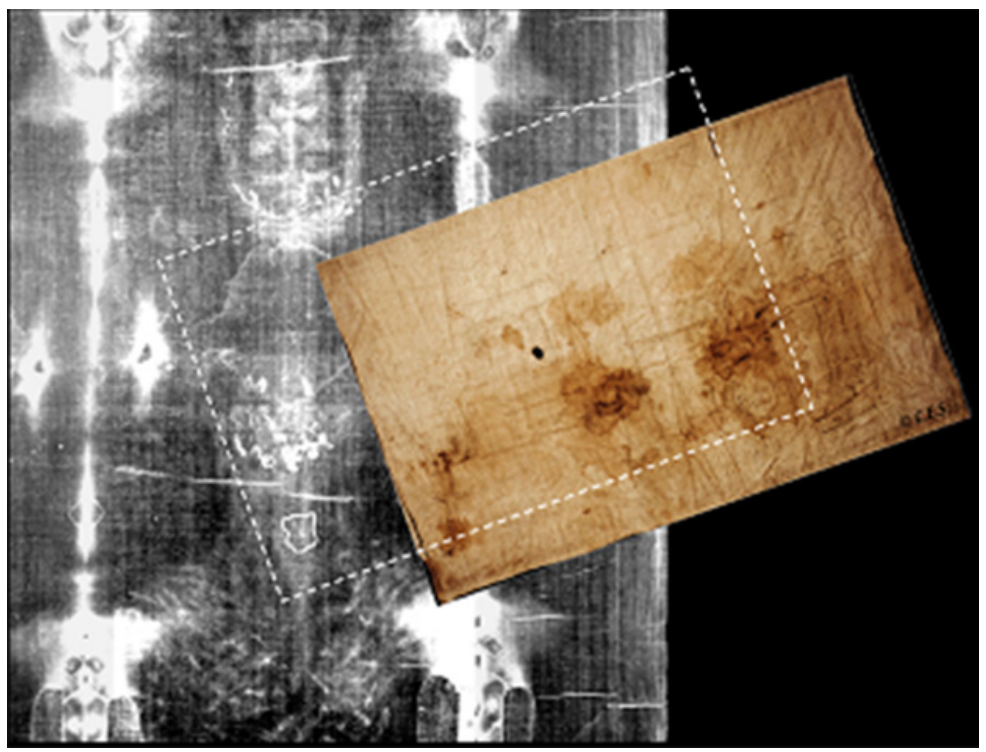

Figure 11. Overlap of the crown of thorn wounds at the nape area in Sudarium and Shroud highlighting the "loose ponytail".

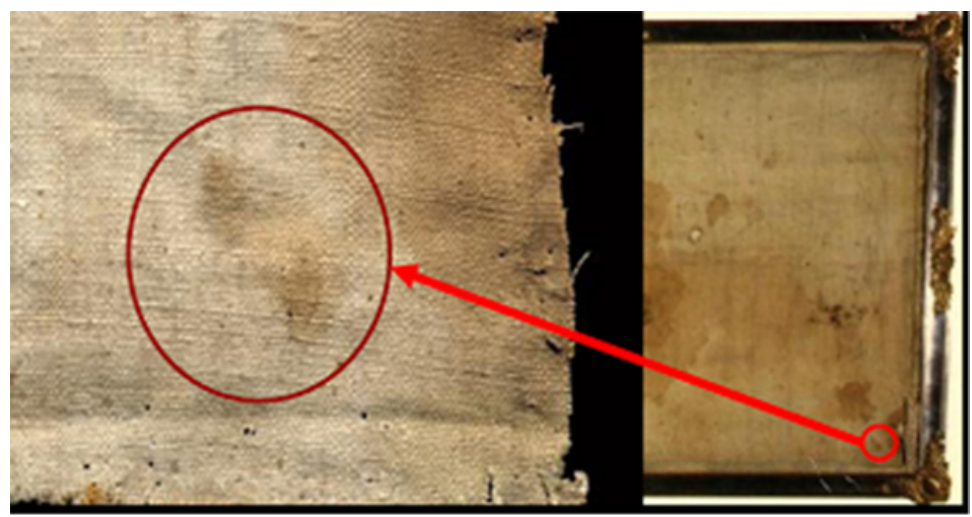

Figure 12. Supposed scourge bloodstains in the Sudarium seen at its front side.

case of the Shroud of Turin, the image of this hair bundle would be transferred to the Italian cloth soon after. We think this is the most plausible explanation for existence of the Man of the Shroud's hair tuft.

The second coincidence that we would like to recall is the possible scourge mark found in the Sudarium. We summarize here after the study of Sánchez [8]. The detailed study of the area close to the lower left corner of the reverse side shows two small bloodstains. The smaller stain is roughly $5.6 \mathrm{~mm}$ in diameter and the largest one, $11.9 \mathrm{~mm}$. The distance between them is $2.5 \mathrm{~mm}$, and the distance between the extreme points of both together is $21.2 \mathrm{~mm}$. These bloodstains are also perceived in the front side (Fig. 12). There is a geometrical compatibility of these stains with the size and shape of the scourge marks observed in the Shroud of Turin.

If this area of the Sudarium is superimposed on the image of the Shroud of Turin image to match the wounds caused by the crown of thorn at the nape, the bloodstains under discussion lie in the transition 
zone between the neck and the upper back very near the middle. In the Turin Shroud image, the expected correspondent scourge marks might be invisible because the hair covered the supposed wound at the same point. On the other hand, it is also possible that the scourge marks of the Sudarium correspond to another stains observable in the Shroud. We admit the possibility that the hair bundle of the Man of the Sudarium was displaced towards his left side and, in this position; it could have received the imprint of other bleeding injury now visible in the Shroud.

For example, there is a scourge mark in the upper back of the Man of the Shroud, lightly to his left whose distance from the crown of thorn wounds is similar to the corresponding distance measured in the Sudarium of Oviedo $(150 \mathrm{~mm})$. If these marks found in the Sudarium are confirmed to be scourge bloodstains, it would be a new impressive coincidence between the two cloths attributed to Jesus Christ.

\section{Conclusion}

The Sudarium of Oviedo and the Shroud of Turin are two relics attributed to Jesus Christ that show a series of amazing coincidences previously described. These similarities suggest that both cloths were used by the same personality.

In this contribution, we describe the X-ray fluorescence analysis performed on the Sudarium and we highlight a new fascinating coincidence with the Shroud and with the place of the Passion. Among the chemical elements detected, the concentration of $\mathrm{Ca}$ is the most reliable one. It is associated to soil dust and it shows a significantly higher presence in the areas with bloody stains. This fact allows us to conclude that the main part of the $\mathrm{Ca}$ located in the stained areas was fixed to the cloth when the physiological fluids were still fresh or soon after. As the stains have been correlated with the anatomical part of the deceased man, the amount of $\mathrm{Ca}$ can also be related with his anatomical features. The highest content of $\mathrm{Ca}$ is observed close to the tip of the nose, indicating unexpected soil dirt in this part of the anatomy. A particular presence of dust was also found in the same place in the Shroud providing a new and astonishing coincidence between both cloths.

The low concentration of $\mathrm{Sr}$ traces in the Sudarium, even lower in the stained areas, matches also well with the type of limestone characteristic from the Calvary in Jerusalem.

This new finding complements two other recently publicized: The ponytail shape of the Man of the Shroud hair, whose origin is justified by the use of the Sudarium of Oviedo and the alleged presence of a scourge mark in this cloth.

Such a gathering of evidences strengthens the tradition that both cloths have wrapped the same body, that of Jesus of Nazareth.

We would like to acknowledge the council of canons owners of the Sudarium for allowing us to test their "treasure". We are also grateful to Florentino Diez and Atanasio Macora for providing the Calvary samples. We thank José Luis Martínez, who generously performed the analysis of some Calvary samples and helped us with the assessment of the results. Finally, we thank M. Jesús Serra for her comments and correction of the English writing.

\section{References}

[1] M. Guscin, The Oviedo Cloth. Cambridge: Lutterworth Press, 1998

[2] Rodríguez-Almenar J.M, El Sudario de Oviedo, Pamplona: Ediciones Universidad de Navarra, S.A. (EUNSA), 2000

[3] B. Wilson, I. Schwortz, The Turin Shroud: The Illustrated Evidence. London: Michael O'Mara Books, 2000, p. 42 
[4] K. Stevenson, G. Habermas, Dictamen sobre la Sábana Santa de Cristo, $3^{\text {a }}$ ed. Planeta, 1998, p. 49

[5] C. Barta, "Estudio Comparativo Sudario de Oviedo - Síndone de Turín," in II International Congress for the Sudarium of Oviedo, 13 to 15 april 2007, University of Oviedo, 2007, pp. 393-423

[6] J. L. Fernández, "The Sudarium of Oviedo and the Turin Shroud. A Question of Authenticital," in International Workshop on the Scientific approach to the Achertopoietos Images, ENEA Frascati, Italy, 4-6 May 2010, no. Section 3

[7] C. Barta, "Aproximación científica a las reliquias de Cristo: Sudario de Oviedo y Síndone de Turín," in Ciencia, humanismo y creencia en una sociedad plural. 13 to 14 October 2011. University of Oviedo. Oviedo, 2012, pp. 213-222

[8] A. Sánchez-Hermosilla, "The Sudarium of Oviedo and the Turin Shroud," in First International Congress on the Holy Shroud in Spain. Valencia, Spain. 28th-30th April 2012, 2012

[9] C. Barta, "The Sudarium of Oviedo and the Man on the Shroud's ponytail," Shroud Newsletter No. 66, 2007

[10] Villalaín J.D, "Síntesis ¿Cómo se utilizó el Sudario de Oviedo?," in II International Congress for the Sudarium of Oviedo, 13 to 15 april 2007. University of Oviedo, 2007, pp. 279-294

[11] F. Montero, "Sudario de Oviedo. Descripción Química y Microscópica. Elementos Encontrados," in International Congress for the Sudarium of Oviedo, Oviedo, 29, 30 y 31 de octubre de 1994, 1994, pp. 67-82

[12] R.A. Morris, L.A. Schwalbe, and J.R. London, "X-ray fluorescence investigation of the shroud of turin," X-Ray Spectrom., vol. 9, no. 2, p. 44, Table 1, 1980

[13] R. Bucklin, “The Shroud of Turin: Viewpoint of a Forensic Pathologist," Shroud Spectr. Int., no. Dec. 1982, 1982

[14] R. Bucklin, "Legal Medicine annual.” W.B. Sauder, Philadelphia, 1982

[15] S. Pellicori and M. Evans, "The Shroud of Turin through the microscope," Archaeology, vol. January/Fe, pp. 35-43, 1981

[16] L.A. Schwalbe and R.N. Rogers, "Physics and Chemistry of the Shroud of Turin: A Summary of the 1978 Investigation," Anal. Chim. Acta, vol. 135, no. 1, pp. 3-49, 1982

[17] Villalaín J.D, "Estudio Hematológico Forense realizado sobre el Santo Sudario de Oviedo, Sudario del Señor," in I International Congress for the Sudarium of Oviedo, Oviedo, 29, 30 y 31 de octubre de 1994, 1994, p. 142 